BNL-111991-2016-JA

\title{
Oxidation and Reduction Under Cover: Chemistry at the Confined Space between Ultra-Thin Nanoporous Silicates and $R u(0001)$
}

\author{
J. Anibal Boscoboinik \\ Jian-Qiang Zhong ${ }^{1}$, John Kestell ${ }^{1}$, Iradwikanari Waluyo ${ }^{2}$, Stuart Wilkins ${ }^{2}$, Claudio \\ Mazzoli', Andi Barbour ${ }^{2}$, Konstantine Kaznatcheev ${ }^{2}$, Meera Shete ${ }^{3}$, Michael \\ Tsapatsis ${ }^{3}$, J. Anibal Boscoboinik ${ }^{1}$ \\ ${ }^{1}$ Center for Functional Nanomaterials, Brookhaven National Laboratory, Upton, NY \\ ${ }^{2}$ Photon Science Division, National Synchrotron Light Source II, Upton, NY \\ ${ }^{3}$ Department of Chemical Engineering and Materials Science, University of \\ Minnesota, 421 Washington Avenue SE, Minneapolis, MN
}

Submitted to the Journal of Physical Chemistry

Center for Functional Nanomaterials

Brookhaven National Laboratory

\section{U.S. Department of Energy Office of Basic Energy Sciences}

\footnotetext{
Notice: This manuscript has been authored by employees of Brookhaven Science Associates, LLC under Contract No. DE- SC0012704 with the U.S. Department of Energy. The publisher by accepting the manuscript for publication acknowledges that the United States Government retains a non-exclusive, paid-up, irrevocable, worldwide license to publish or reproduce the published form of this manuscript, or allow others to do so, for United States Government purposes.
} 


\section{DISCLAIMER}

This report was prepared as an account of work sponsored by an agency of the United States Government. Neither the United States Government nor any agency thereof, nor any of their employees, nor any of their contractors, subcontractors, or their employees, makes any warranty, express or implied, or assumes any legal liability or responsibility for the accuracy, completeness, or any third party's use or the results of such use of any information, apparatus, product, or process disclosed, or represents that its use would not infringe privately owned rights. Reference herein to any specific commercial product, process, or service by trade name, trademark, manufacturer, or otherwise, does not necessarily constitute or imply its endorsement, recommendation, or favoring by the United States Government or any agency thereof or its contractors or subcontractors. The views and opinions of authors expressed herein do not necessarily state or reflect those of the United States Government or any agency thereof. 


\title{
Oxidation and Reduction Under Cover: Chemistry at the Confined Space between Ultra-Thin Nanoporous Silicates and Ru(0001)
}

\author{
Jian-Qiang Zhong ${ }^{1}$, John Kestell ${ }^{1}$, Iradwikanari Waluyo $^{2}$, Stuart Wilkins ${ }^{2}$, Claudio \\ Mazzoli $^{2}$, Andi Barbour ${ }^{2}$, Konstantine Kaznatcheev $^{2}$, Meera Shete $^{3}$, Michael Tsapatsis ${ }^{3}$, \\ J. Anibal Boscoboinik ${ }^{1 *}$
}

${ }^{1}$ Center for Functional Nanomaterials, Brookhaven National Laboratory, Upton, NY 11973, United States

${ }^{2}$ Photon Science Division, National Synchrotron Light Source II, Upton, NY 11973, United States

${ }^{3}$ Department of Chemical Engineering and Materials Science, University of Minnesota, 421 Washington Avenue SE, Minneapolis, MN, 55455 United States

*Corresponding author. E-mail: jboscoboinik@bnl.gov (J. Anibal Boscoboinik). Phone:

+1 631 344-7272. Fax: +1 631 344-3093. 
ABSTRACT. The oxidation and reduction of $\mathrm{Ru}(0001)$ surfaces at the confined space between two-dimensional nanoporous silica frameworks and $\mathrm{Ru}(0001)$ have been investigated using synchrotron-based ambient pressure $\mathrm{x}$-ray photoelectron spectroscopy (AP-XPS). The porous nature of the frameworks and the weak interaction between the silica and the ruthenium substrate allow oxygen and hydrogen molecules to go through the nanopores and react with the metal at the interface between the silica framework and the metal surface. In this work, three types of two-dimensional silica frameworks have been used to study their influence in the oxidation and reduction of the ruthenium surface at elevated pressures and temperatures. These frameworks are bilayer silica ( $0.5 \mathrm{~nm}$ thick), bilayer aluminosilicate $(0.5 \mathrm{~nm}$ thick) and zeolite MFI nanosheets ( $3 \mathrm{~nm}$ thick). It is found that the silica frameworks stay essentially intact under these conditions, but they strongly affect the oxidation of ruthenium, with the 0.5 nm thick aluminosilicate bilayer completely inhibiting the oxidation. The latter is believed to be related to the lower chemisorbed oxygen content arising from electrostatic interactions between the negatively charged aluminosilicate framework and the $\operatorname{Ru}(0001)$ substrate. 


\section{INTRODUCTION}

The influence of nanoscale confined spaces in the chemistry and molecular transport phenomena is well known in the field of microporous materials and in particular for zeolites, for which different frameworks made of the same elements can exhibit dramatically different behaviors. Less known is the case of two-dimensional confined nano-spaces, which provide a new playground for fundamental studies in physics and chemistry. This is especially true for the case of two-dimensional (2D) materials that interact with the surface of a metal single crystal through weak forces, such as van der Waals interactions, allowing tunability in the distance between the solid surface and the 2D layer when molecules are intercalated between them. One of such cases is that of the intercalation of oxygen between graphene and $\mathrm{Ru}(0001) .{ }^{1-2}$ In work by Sutter et al. oxygen dissociates and chemisorbs on the ruthenium surface decoupling graphene from the metal substrate and etches away the graphene when the temperature is raised above $450{ }^{\circ} \mathrm{C}$. Those studies were further expanded on $\mathrm{Pt}(111)$ substrate and even reactions "under cover" were studied. ${ }^{3}$ The recent observation that a graphene layer on transition metal surfaces limits the intercalation of oxygen at the interface has raised the attention of the corrosion chemistry community, since these studies showed that such ultra-thin layer can greatly inhibit oxidation of the metal onto which it is grown. ${ }^{4}$ While the particular case of graphene as an anti-corrosion coating limits its practical application, given that the passivating graphene layer itself can be etched away by oxygen at 
elevated temperatures, the idea can be expanded to more robust low-cost ultra-thin materials, such as silicates.

Two-dimensional ultrathin silica films with well-defined atomic structures have been recently synthesized, in work arising from the wide interest there is in using these materials as surface science model systems of heterogeneous catalysts, in particular for the case of zeolites. ${ }^{5-6}$ In the past decade, intensive research efforts have been devoted to the preparation of well-ordered crystalline silica films on diverse metals, such as $\operatorname{Mo}(112), \operatorname{Ni}(111), \operatorname{Pd}(100), \operatorname{Pt}(111)$, and $\operatorname{Ru}(0001){ }^{7-13}$ In particular, free-standing silicate and aluminosilicate bilayer with corner-sharing $\left[\mathrm{SiO}_{4}\right]$ tetrahedra have been successfully grown on noble metal substrates, in which the silica bilayer only weakly interacts with the support via van der Waals forces. ${ }^{12}$ In fact, recent theoretical work by the Sauer and Pacchioni groups has shown how the thickness of this confined space can be tuned by introducing $\mathrm{CO}$ as an adsorbate at the interface. ${ }^{14}$ The minimized interaction between the metallic substrate and the ultrathin silica films enables the study of fundamental aspects of chemical and physical processes at confined spaces by using these model systems. ${ }^{5}$ Moreover, it also provides a confined space for small molecules to intercalate and react at the interface. ${ }^{15-16}$ An alternative to the aforementioned "surface science" approach to preparing 2D silicates comes from the zeolite community. It was recently demonstrated that $3 \mathrm{~nm}$ nanosheets can be produced by exfoliation of a multilamellar MFI zeolite ${ }^{17}$ and then deposited onto a silicon surface using a Langmuir-Schaefer method. ${ }^{18}$ These zeolite nanosheets have received a lot of 
attention due to their potential application as membranes for separation of molecules, such as the case of different xylene isomers. ${ }^{19}$ Applications in catalysis are also envisioned, such as in the case of self-pillared Sn-MFI nanosheets for the isomerization of glucose and lactose. ${ }^{20}$

In this work, we use ambient pressure x-ray photoelectron spectroscopy (AP-XPS) to study the "under cover" oxidation and reduction of $\mathrm{Ru}(0001)$ surfaces. Three types of silica films (i.e., bilayer silicate, ${ }^{21}$ bilayer aluminosilicate ${ }^{22}$ and MFI nanosheets ${ }^{18}$ ) have been used to cover the $\mathrm{Ru}(0001)$. Figure 1 shows schematics of the structures that are compared in this work. The silica and aluminosilicate bilayers have a previously reported thickness of $\sim 0.5 \mathrm{~nm}$, while the MFI nanosheet has a thickness of $3 \mathrm{~nm}$. Their influence on the oxidation and reduction of the $\mathrm{Ru}(0001)$ surface is explored.
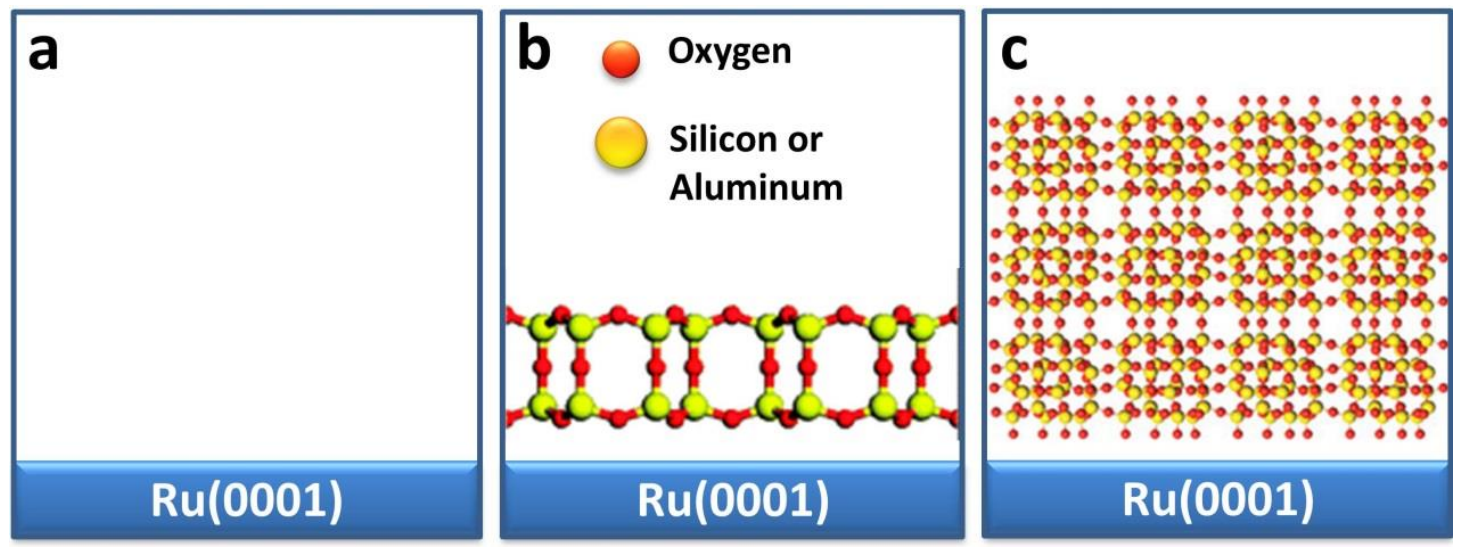

Figure 1. (a) Bare $\mathrm{Ru}(0001)$, (b) $\mathrm{Ru}(0001)$ covered by a $0.5 \mathrm{~nm}$ thick (alumino)silicate bilayer structure and (c) $\mathrm{Ru}(0001)$ covered by a $3 \mathrm{~nm}$ thick MFI zeolite nanosheet. 


\section{EXPERIMENTAL SECTION}

The $\mathrm{Ru}(0001)$ single crystal surface was cleaned with cycles of $\mathrm{Ar}^{+}$sputtering and annealing at $1400 \mathrm{~K}$. The surface was then exposed to $3 \times 10^{-6} \mathrm{mbar}_{2}$ at $1200 \mathrm{~K}$ in order to form a chemisorbed $(2 \times 2)-3 \mathrm{O} / \mathrm{Ru}(0001)$ overlayer. The bilayer silicate and aluminosilicate films were grown on the oxygen pre-covered ruthenium surface as described in detail elsewhere. ${ }^{12-13}$ Briefly, Si (and Al) was thermally evaporated onto the $(2 \times 2)-3 \mathrm{O} / \mathrm{Ru}(0001)$ surface at room temperature under $2 \times 10^{-7} \mathrm{mbar}$ of $\mathrm{O}_{2}$, followed by oxidation at $1200 \mathrm{~K}$ in $3 \times 10^{-6} \mathrm{mbar}_{2}$ for 10 minutes and then slowly cooled down in $\mathrm{O}_{2}$ environment. The $3 \mathrm{~nm}$ thick MFI nanosheets were deposited onto the $\mathrm{Ru}(0001)$ surface using a Langmuir-Schaefer method described in reference ${ }^{18}$. The sample was then heated to $773 \mathrm{~K}$ in a $20 \mathrm{cc} / \mathrm{min}$ flow of $\mathrm{O}_{2}$ at $1 \mathrm{Atm}$ pressure in a tube furnace to remove carbonaceous contamination from the synthesis and exfoliation process. The removal of carbon was confirmed by XPS.

AP-XPS measurements were carried out at the Coherent Soft X-ray Scattering and Spectroscopy Beamline (CSX-2) of the National Synchrotron Light Source II (NSLS-II). The main chamber (base pressure $2 \times 10^{-9}$ mbar) of the end-station was equipped with a differentially pumped hemispherical analyzer (Specs Phoibos 150 NAP), which was offset by $70^{\circ}$ from the incident synchrotron light and $20^{\circ}$ from the surface normal of the sample. A photon energy of $750 \mathrm{eV}$ was used in our studies, which was calibrated and referenced to the Fermi level of the $\mathrm{Ru}(0001)$ substrates. The ruthenium crystal was mounted on a ceramic button heater and the temperature was 
monitored through a type $\mathrm{K}$ thermocouple underneath the crystal. The $\mathrm{O}_{2}$ and $\mathrm{H}_{2}$ gases were separately introduced into the main chamber through precision leak valves for the oxidation and reduction reactions.

\section{RESULTS AND DISCUSSION}

The structures of chemisorbed oxygen on $\mathrm{Ru}(0001)$ have been studied extensively in the past, including the cases of $\mathrm{p}(2 \times 2)-\mathrm{O}^{23}, \mathrm{p}(2 \times 1)-\mathrm{O}^{24},(2 \times 2)-3 \mathrm{O}^{25},(1 \times 1)-\mathrm{O}^{26}$. As previously reported, bilayer silicate films can be grown on the $(2 \times 2)-3 \mathrm{O} / \mathrm{Ru}(0001)$ surface, and it is believed that chemisorbed oxygen prevents Si atoms from diffusing into and alloying with $\mathrm{Ru}(0001)$ during the thermal evaporation. ${ }^{13}$ The "as-deposited" $\mathrm{SiO}_{\mathrm{x}}$ film is later annealed at $1200 \mathrm{~K}$ in $3 \times 10^{-6} \mathrm{mbar}_{2}$ for 10 minutes to crystallize the bilayer silica structure. Si species are fully oxidized to $\mathrm{Si}^{4+}$ as evident by the XPS, showing a binding energy of $103.10 \mathrm{eV}$ for the Si $2 \mathrm{p}$ core level (not shown). The corresponding $\mathrm{O} 1 \mathrm{~s}$ spectra show a main peak at $532.25 \mathrm{eV}$ and a shoulder peak at $529.80 \mathrm{eV}$ (Figure 2a, bottom spectrum), which are assigned to the Si-O-Si linkages in the bilayer silicate film and the chemisorbed oxygen $(\mathrm{O}-\mathrm{Ru})$ on ruthenium respectively. ${ }^{27}$ A shoulder peak of $\mathrm{Ru} 3 \mathrm{~d}_{5 / 2}$ at $280.90 \mathrm{eV}$ further confirms the existence of the chemisorbed oxygen at the interface (Figure $2 b$ ). ${ }^{28}$ It should be noted that the very small peaks around the $\mathrm{Ru} 3 \mathrm{~d}_{3 / 2}$ peak (Figure $2 \mathrm{~b}, 283.60 \mathrm{eV}$ and $285.25 \mathrm{eV}$ ) could be assigned to carbide-like species and amorphous carbon respectively, which might emerge during the film preparation. ${ }^{29}$ The area of the $529.80 \mathrm{eV} \mathrm{O} 1 \mathrm{~s}$ peak, corresponding to $\mathrm{O}-\mathrm{Ru}$ species, was integrated and a chemisorbed oxygen coverage of 
$\sim 0.3 \mathrm{ML}$ was estimated by comparing with the $0.75 \mathrm{ML}$ of $(2 \times 2)-3 \mathrm{O} / \mathrm{Ru}(0001)$ taking into account the attenuation by the silicate film in the calculation. This is in agreement with previous experimental and theoretical work that suggests that the as-prepared film contains on average between two and four interfacial $\mathrm{O}$ atoms per unit cell, which would correspond to a coverage in the range between $0.25 \mathrm{ML}$ and $0.5 \mathrm{ML}^{27}$
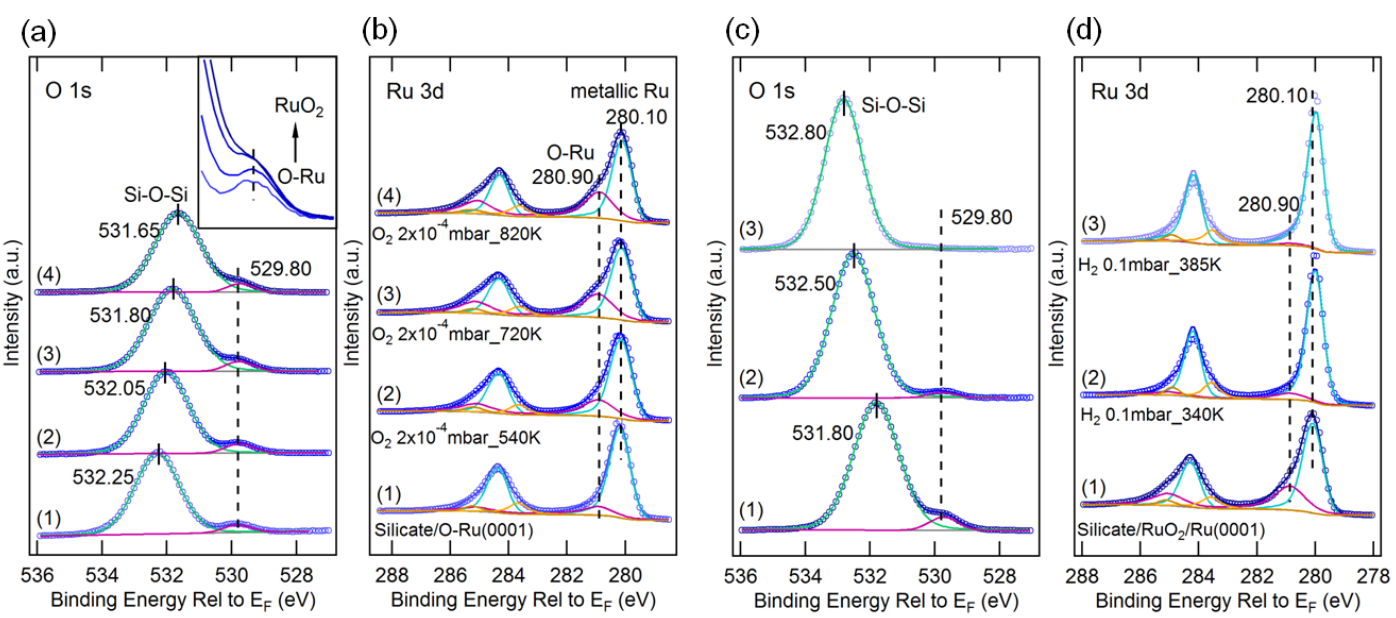

Figure 2. Oxidation (a-b) and reduction (c-d) of the bilayer silicate film on oxygen chemisorbed $\mathrm{Ru}(0001)$ surface. The AP-XPS core level spectra of (a) O 1s and (b) Ru $3 \mathrm{~d}$ are taken under $2 \times 10^{-4}$ mbar of $\mathrm{O}_{2}$ (The bottom spectra are obtained in UHV prior to the oxygen exposure and the inset in (a) shows the details of the $\mathrm{O} 1 \mathrm{~s}$ shoulder peak at $529.80 \mathrm{eV}$ ). The AP-XPS core level spectra of (c) O 1s and (d) Ru 3d are taken under 0.1 mbar of $\mathrm{H}_{2}$ (The bottom spectra are obtained in UHV prior to the hydrogen exposure).

This "as-prepared" bilayer silicate film was then annealed in $2 \times 10^{-4}$ mbar of $\mathrm{O}_{2}$ at increasing temperatures (Figure $2 \mathrm{a}$ and $2 \mathrm{~b}$ ). Note that under this conditions, previous AP-XPS experiments on bare $\mathrm{Ru}(0001)$ showed the formation of $\mathrm{RuO}_{2}{ }^{15}$ It is 
interesting to see that the $\mathrm{O} 1 \mathrm{~s}$ from framework Si-O-Si linkages gradually shifts to the lower binding energy by $\sim 0.6 \mathrm{eV}$, while the $\mathrm{O}-\mathrm{Ru}$ related $\mathrm{O} 1 \mathrm{~s}$ remains almost unchanged. The $\mathrm{O} 1 \mathrm{~s}$ shift is accompanied by a similar Si $2 \mathrm{p}$ peak shift upon oxidation. Both the intensity and the full width half maximum (FWHM) of the O $1 \mathrm{~s}$ and $\mathrm{Si} 2 \mathrm{p}$ remain unchanged, indicating that the chemical compositions and bonding structures of the silicate film stay intact. The decrease in binding energy is mostly attributed to the changes of the chemical states on the Ru substrate. ${ }^{15,27,30}$ While this effect in the binding energy with the oxygen coverage has been reported before, no clear explanation has been given to explain the origin of this shift and a manuscript analyzing this effect in detail is in preparation. As shown in Figure 2a and 2b, the intensities of the components of the $\mathrm{O} 1 \mathrm{~s}$ and $\mathrm{Ru} 3 \mathrm{~d}$ from the $\mathrm{O}-\mathrm{Ru}$ moiety increase by a factor of 2.5 from the "as-prepared" bilayer silicate to the film annealed at $820 \mathrm{~K}$ in $2 \times 10^{-4}$ mbar of $\mathrm{O}_{2}$ resulting in an oxygen coverage of $\sim 0.75 \mathrm{ML}$, when the O-coverage of the "as-prepared" bilayer silicate is taken as reference. While this coverage corresponds to that of $(2 \times 2)-3 \mathrm{O}$ overlayer, previous TPD experiments on a silica-covered $\mathrm{Ru}(0001)$ suggest that part of this oxygen is more weakly adsorbed than that of $(2 \times 2)-3 \mathrm{O}$ overlayer on bare $\mathrm{Ru}(0001)$, and even the existence of a small amount of $\mathrm{RuO}_{2}$ phase has also been suggested. ${ }^{15}$ However, the fact that the lower energy shoulder of the $\mathrm{O} 1 \mathrm{~s}$ peak remains at $529.8 \mathrm{eV}$ (Figure 2a) indicates that there is no formation on an oxide. The possibility of the presence of some subsurface oxygen is considered and that might be in fact the origin of the more weakly bound $\mathrm{O}$ species found in previous TPD 
experiments. Note that both chemisorbed oxygen and subsurface oxygen result in similar shifts to higher binding energies of the $\mathrm{Ru} 3 \mathrm{~d}_{5 / 2}$ peak. ${ }^{28}$ The existence of a $\mathrm{RuO}_{2}$ oxide phase can be confidently excluded since this would be accompanied by the evolution of a satellite of the $\mathrm{Ru} 3 \mathrm{~d}_{5 / 2}$ peak at $282.7 \mathrm{eV},{ }^{31}$ which is not observed in this case.

The removal of oxygen from the surface was then followed by exposure to $0.1 \mathrm{mbar}$ of $\mathrm{H}_{2}$ (Figures $2 \mathrm{c}$ and $2 \mathrm{~d}$ ). We can see that all silicate-related core levels shift to higher binding energies by $\sim 1.0 \mathrm{eV}$ upon a complete reduction reaction at $385 \mathrm{~K}$. However, the chemisorbed oxygen $(\mathrm{O}-\mathrm{Ru})$ related $\mathrm{O} 1 \mathrm{~s}$ and $\mathrm{Ru} 3 \mathrm{~d}$ peaks still stay at the same positions. The significantly attenuated peaks indicate that most of the chemisorbed oxygen at the interface desorbs upon reduction, resulting in a silicate $/ \mathrm{Ru}(0001)$ interface. ${ }^{27}$ The fact that virtually all Ru-bound oxygen is removed at such low temperature in the presence of $\mathrm{H}_{2}$ is remarkable when compared to the vacuum annealing of these films, for which a significant amount of oxygen remains on the surface when heating to $1200 \mathrm{~K}$, the maximum temperature achievable before the film starts decomposing. 
(a)

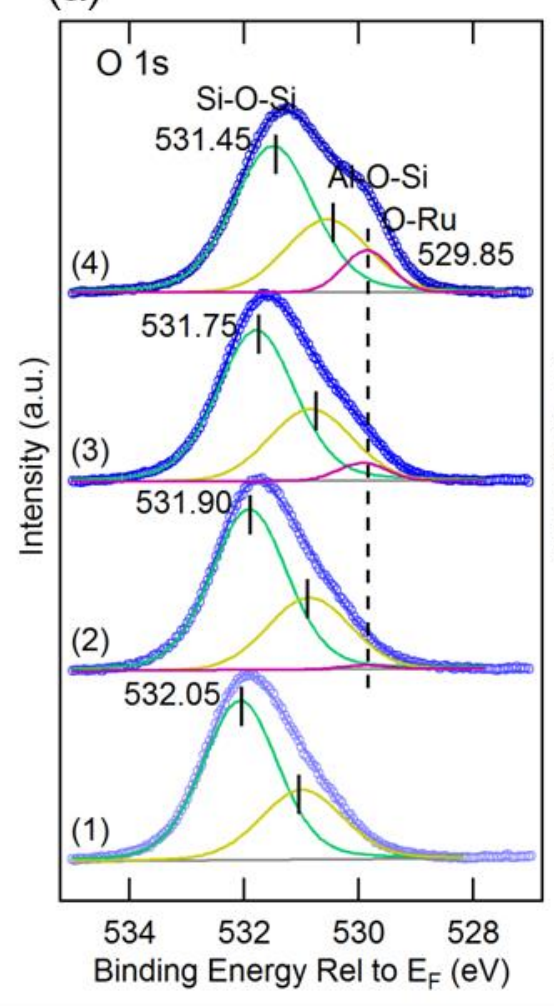

(b)

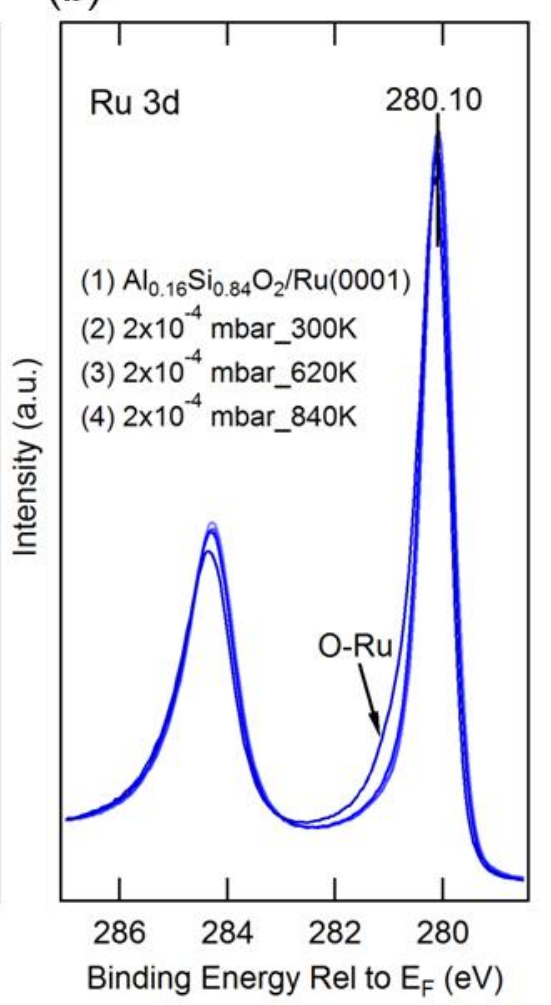

Figure 3. Oxidation through bilayer aluminosilicate film on $\mathrm{Ru}(0001)$ surface. The AP-XPS core level spectra of (a) $\mathrm{O} 1 \mathrm{~s}$ and (b) Ru $3 \mathrm{~d}$ are taken under $2 \times 10^{-4} \mathrm{mbar}$ of $\mathrm{O}_{2}$ at increasing temperatures.

To gain more insights on the effect of different silicates on the oxidation and reduction of $\mathrm{Ru}(0001)$, we further investigated aluminosilicate on $\mathrm{Ru}(0001)$ and MFI nanosheets on $\mathrm{Ru}(0001)$. The aluminosilicate film consists of a crystalline bilayer network of $\left[\mathrm{SiO}_{4}\right]$ and $\left[\mathrm{AlO}_{4}^{-1}\right]$ tetrahedra $\left(\mathrm{Al}_{\mathrm{x}} \mathrm{Si}_{1-\mathrm{x}} \mathrm{O}_{2}\right)$, which is weakly bound to the $\mathrm{Ru}(0001)$ substrate. $^{12}$ In this work, an aluminosilicate film with stoichiometry of $\mathrm{Al}_{0.16} \mathrm{Si}_{0.84} \mathrm{O}_{2}$ was prepared. The "as-prepared" aluminosilicate film was first reduced in hydrogen to remove all the chemisorbed oxygen at the interface. As shown in Figure $3 \mathrm{a}$, the $\mathrm{O}$ 1s of a clean $\mathrm{Al}_{0.16} \mathrm{Si}_{0.84} \mathrm{O}_{2} / \mathrm{Ru}(0001)$ interface develops into two peaks at 532.05 
$\mathrm{eV}$ and $531.05 \mathrm{eV}$, which are assigned to the Si-O-Si and Al-O-Si linkages respectively. ${ }^{12}$ By oxidizing the film in $2 \times 10^{-4} \mathrm{mbar}_{2}$, a third oxygen peak appears at a binding energy of $529.85 \mathrm{eV}$ which is attributed to the chemisorbed oxygen on $\mathrm{Ru}(0001)$, as described before for the case of the silica framework. Similarly, all core levels in the aluminosilicate framework shift to lower binding energies by $\sim 0.6 \mathrm{eV}$, while the chemisorbed oxygen peak still remains at the same binding energy. During subsequent $\mathrm{H}_{2}$ exposure at $380 \mathrm{~K}$ (data not shown), all aluminosilicate-related peaks shift back to the higher binding energy by $\sim 0.6 \mathrm{eV}$. Moreover, the $\mathrm{O} 1 \mathrm{~s}(\mathrm{O}-\mathrm{Ru})$ and $\mathrm{Ru}$ $3 \mathrm{~d}(\mathrm{O}-\mathrm{Ru})$ peaks disappear again.

As we have recently reported, the aluminosilicate films can largely suppress the $\mathrm{Ru}$ oxidation. ${ }^{15}$ One possible reason is that the distance between the aluminosilicate film and ruthenium substrate is smaller as compared to the silicate/Ru interface due to the $\mathrm{Al}$ substitutions in the bottom layer. ${ }^{12}$ Note that the $\mathrm{Al}$ substitutions introduce one negative framework charge per $\mathrm{Al}$ atom. While in zeolites this charge is usually compensated by a cationic species, it is possible that in the case of the $2 \mathrm{D}$ aluminosilicate, the top layer $\mathrm{Ru}$ provides the charge compensation, which would introduce additional electrostatic forces between the framework and the $\mathrm{Ru}(0001)$ surface, which could explain the lower oxygen coverage obtained when compared to the case of the silica bilayer framework. The degree of the oxidization at the silicate/Ru and aluminosilicate/Ru interfaces can be roughly compared from the $\mathrm{Ru} 3 \mathrm{~d}$ signals. The peak intensity ratio between the $\mathrm{O}-\mathrm{Ru}$ and metallic $\mathrm{Ru}$ in aluminosilicate/Ru (38\%) is smaller than that of in 
2D-silicate/ $\mathrm{Ru}(59 \%)$ as shown in Figure $2 \mathrm{~b}$ and Figure $3 \mathrm{~b}$, indicating that ruthenium surface in $2 \mathrm{D}$-aluminosilicate/Ru has a much lower oxygen content.

For the $3 \mathrm{~nm}$ MFI nanosheets on $\mathrm{Ru}(0001)$, the behavior is very different (Figure 4). While for the $0.5 \mathrm{~nm}$ silica and aluminosilicate bilayers, only the $\mathrm{O} 1 \mathrm{~s}$ peak associated with the framework oxygen (Si-O-Si) shifts to lower binding energies when heating in $\sim 10^{-4}$ mbar of $\mathrm{O}_{2}$, for the MFI case, the low binding energy $\mathrm{O}$ 1s peak associated with the chemisorbed oxygen also shifts down in energy, as it can be seen in Figure 4a. This was observed as well in previous work for clean $\mathrm{Ru}(0001)$ upon heating to the same pressure of $\mathrm{O}_{2}$ and it is attributed to the formation of $\mathrm{RuO}_{2} \cdot{ }^{15}$ This is accompanied by attenuation of the $\mathrm{Ru} 3 \mathrm{~d}_{5 / 2}$ peak and the evolution of a new broad peak at $282.70 \mathrm{eV}$ as shown in Figure $4 b$, which corresponds to a previously observed satellite of $R u 3 d_{5 / 2}$ the origin of which was explained by Over and co-workers. ${ }^{31}$ It has been reported that the incorporation of chemisorbed oxygen into the ruthenium bulk only occurs to a limited extent in high vacuum experiments $\left(<10^{-5}\right.$ mbar $) .{ }^{32-33}$ The $282.70 \mathrm{eV} \mathrm{Ru} 3 \mathrm{~d}_{5 / 2}$ satellite peak correlates well with the shift of the low binding energy $\mathrm{O} 1 \mathrm{~s}$ peak and confirms that these two features are related to the formation of $\mathrm{RuO}_{2}$ for the MFI nanosheet-covered $\mathrm{Ru}(0001)$ surface. These observations show that the $\mathrm{Ru}(0001)$ surface can be easily oxidized when covered by MFI nanosheets as opposed to the cases of silica and aluminosilicate bilayer, even though the thickness of the latter two is much smaller than that of MFI, i.e. $0.5 \mathrm{~nm}$ as opposed to $3 \mathrm{~nm}$. This susceptibility to 
oxidation, closer to that of bare $\mathrm{Ru}(0001)$, is attributed to the larger pore size in the MFI frameworks. $^{34}$

(a)

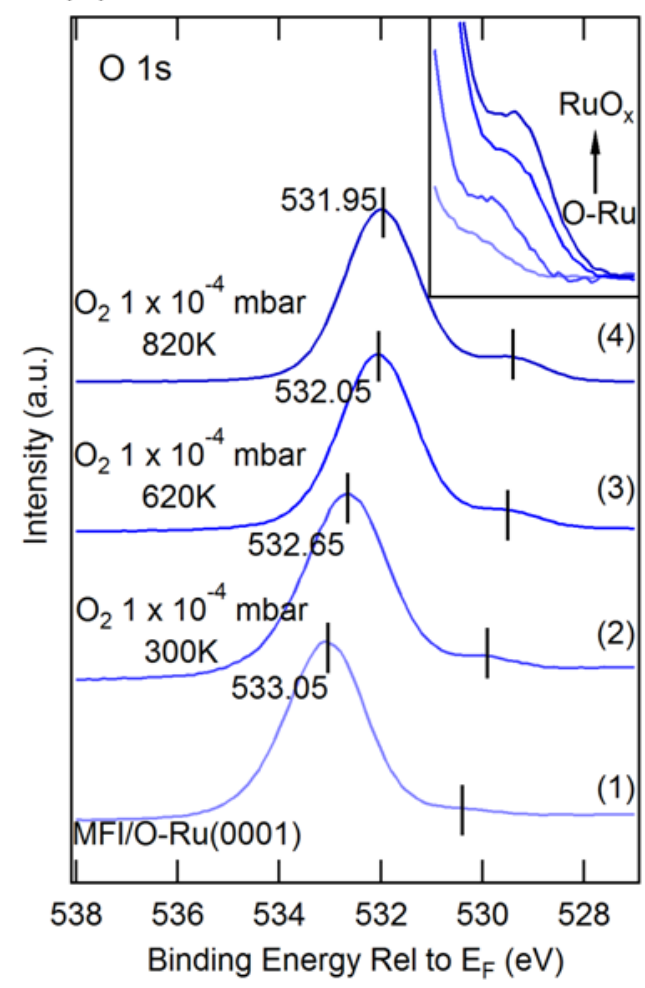

(b)

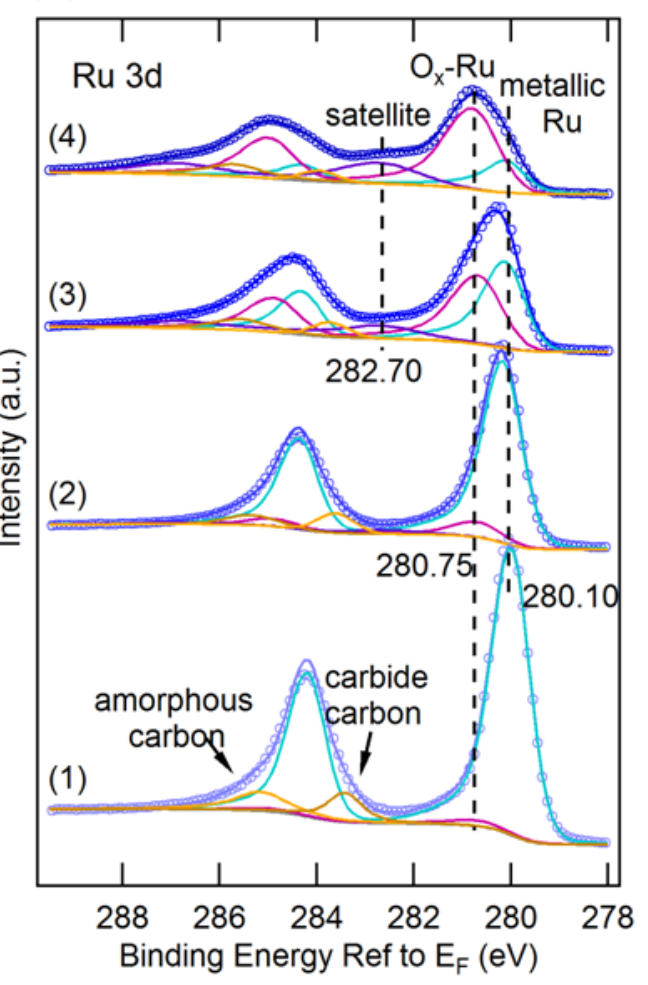

Figure 4. Oxidation through MFI nanosheets on the $\mathrm{Ru}(0001)$ surface. The AP-XPS core level spectra of (a) $\mathrm{O} 1 \mathrm{~s}$ and (b) $\mathrm{Ru} 3 \mathrm{~d}$ are taken under $1 \times 10^{-4}$ mbar of $\mathrm{O}_{2}$ with increasing temperatures.

In order to more easily visualize the difference in the effect of the three different frameworks in the oxidation of $\mathrm{Ru}(0001)$ we have plotted in Figure 5 the oxygen coverage for each case as a function of temperature under elevated pressures of $\mathrm{O}_{2}$ and then in $\mathrm{H}_{2}$ for their reduction. 


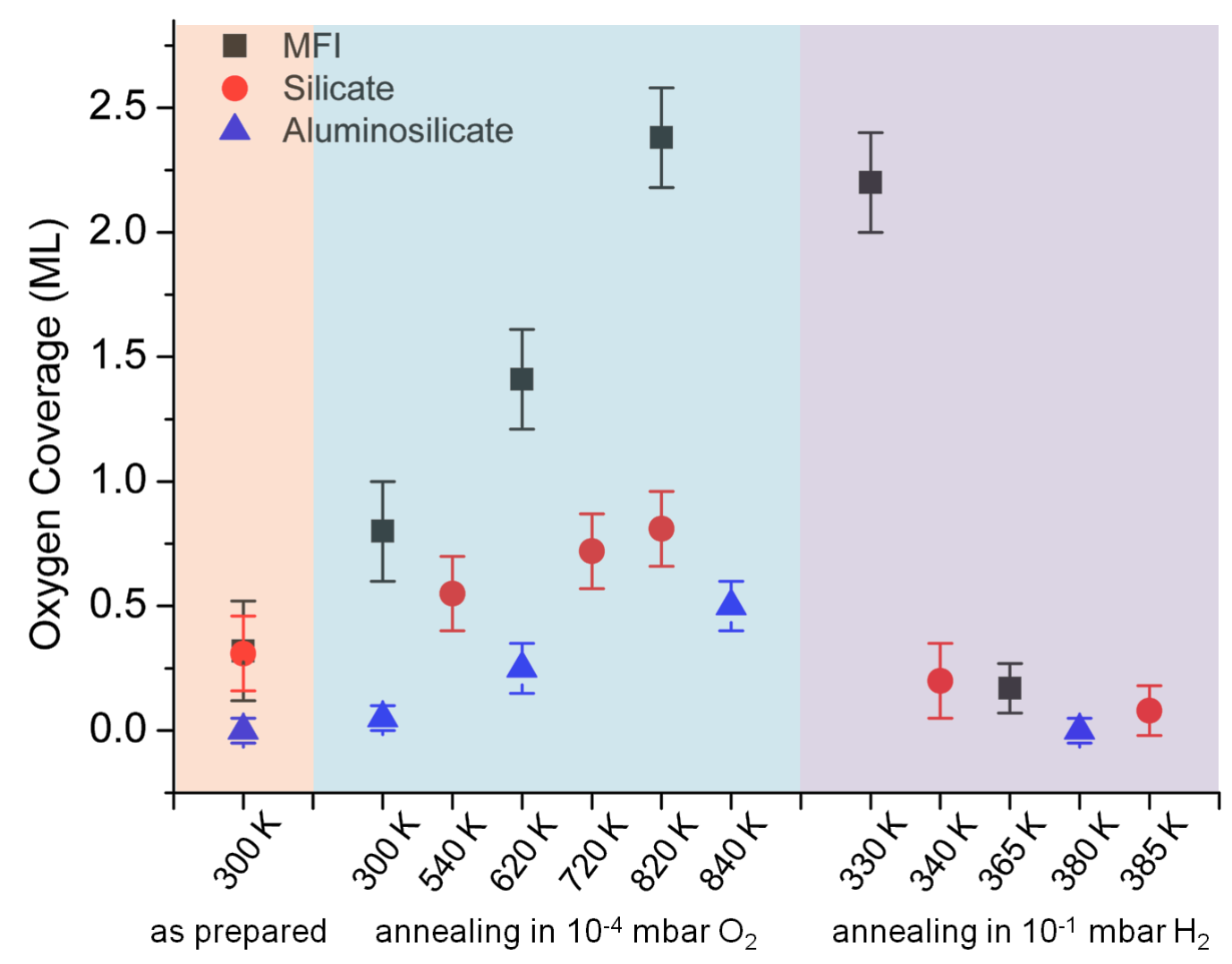

Figure 5. Oxygen coverage, excluding framework oxygen, as a function of temperature under $\mathrm{O}_{2}$ (green panel) and $\mathrm{H}_{2}$ (purple panel) for $\mathrm{Ru}(0001)$ covered by silica bilayer $(\bullet)$, aluminosilicate bilayer $(\boldsymbol{\Delta})$ and MFI nanosheets $(\boldsymbol{\square})$.

The silica films stay essentially intact during the oxidation and reduction reactions as inferred from the unchanged peak shape. While $\mathrm{O}_{2}$ can readily penetrate through all frameworks and dissociates into atomic oxygen on the $\mathrm{Ru}(0001)$ surface, the fact that it only results in the formation of $\mathrm{RuO}_{2}$ for the case of MFI nanosheets is most likely related to the larger pore size of MFI. Additionally, the "tiling" of the MFI nanosheets on the surface will probably leave a relatively small fraction of the $\mathrm{Ru}(0001)$ surface exposed. It was previously suggested that the formation of $\mathrm{RuO}_{2}$ is an autocatalytic process $^{35}$ and it may require enough open $\mathrm{Ru}$ area to facilitate the nucleation, and 
subsequent growth of the oxide. While we believe that the steric effect is responsible for the different chemistry between MFI nanosheets and the bilayer silica and aluminosilicate frameworks, note that the termination of the MFI nanosheets at their boundaries is not well understood and it cannot be discarded that this might also have an effect in the different chemistry. Further surface science studies on the MFI zeolite nanosheet are necessary. However, it is clear from the current study that the bilayer structures, and especially the case of the aluminosilicate, inhibit the oxidation of the $\mathrm{Ru}(0001)$ surface. This could lead to promising applications in the development of ultrathin anti-corrosion coatings in the future.

\section{CONCLUSIONS}

The oxidation of $\mathrm{Ru}(0001)$ covered by different types of well-defined nanoporous silicate structures, namely $\sim 3 \mathrm{~nm}$ MFI nanosheets and $\sim 0.5 \mathrm{~nm}$ bilayer silica and aluminosilicate frameworks, was studied at an $\mathrm{O}_{2}$ pressure of $1 \times 10^{-4} \mathrm{mbar}$ at increasing temperatures using synchrotron-based ambient pressure X-ray photoelectron spectroscopy. This was followed by reduction of the surface by exposure to $\mathrm{H}_{2}$ at elevated pressures. It is found that the thinner $0.5 \mathrm{~nm}$ frameworks inhibit the formation of $\mathrm{RuO}_{2}$. However, the oxide readily forms under the thicker $3 \mathrm{~nm}$ MFI nanosheets. In particular, the case of the aluminosilicate bilayer framework further reduces the maximum amount of oxygen present on the surface to $0.5 \mathrm{ML}$, which is believed to result from the involvement of $\mathrm{Ru}(0001)$ in the charge compensation of the framework. It is suggested that the larger pore openings of the MFI nanosheet leave enough 
ruthenium surface exposed to facilitate the formation of $\mathrm{RuO}_{2}$ through a previously suggested autocatalytic mechanism. This indicates that aluminosilicate coatings as thin as $0.5 \mathrm{~nm}$ can prevent corrosion of a flat surface if no voids are present on the surface.

\section{AUTHOR INFORMATION}

${ }^{*}$ Corresponding author. E-mail: jboscoboinik@bnl.gov (J. Anibal Boscoboinik). Phone: +1 631 344-7272. Fax: +1 631 344-3093.

The authors declare no competing financial interests.

ACKNOWLEDGMENT. Research carried out in part at the National Synchrotron Light Source II and Center for Functional Nanomaterials, Brookhaven National Laboratory, which is supported by the U.S. Department of Energy, Office of Basic Energy Sciences, under Contract No. DE-SC0012704. MFI nanosheet preparation was supported from the Center for Gas Separations Relevant to Clean Energy Technologies, an Energy Frontier Research Center funded by the US Department of Energy, Office of Science, Basic Energy Sciences under Award \# DE-SC000105. J.Z. is supported by BNL LDRD Project No. 15-010. We gratefully acknowledge the support from Kazimierz G., Larry F., Steve B. and Andrew M. at NSLS-II.

\section{REFERENCES}

1. Sutter, P.; Sadowski, J. T.; Sutter, E. A. Chemistry under Cover: Tuning Metal-Graphene Interaction by Reactive Intercalation. J. Am. Chem. Soc. 2010, 132, 8175-8179. 
2. Dong, A.; Fu, Q.; Wei, M.; Liu, Y.; Ning, Y.; Yang, F.; Bluhm, H.; Bao, X. Facile Oxygen Intercalation between Full Layer Graphene and $\mathrm{Ru}(0001)$ under Ambient Conditions. Surf. Sci. 2015, 634, 37-43.

3. Mu, R.; Fu, Q.; Jin, L.; Yu, L.; Fang, G.; Tan, D.; Bao, X. Visualizing Chemical Reactions Confined under Graphene. Angew. Chem. Int. Ed. 2012, 51, 4856-4859.

4. Weatherup, R. S.; D’Arsié, L.; Cabrero-Vilatela, A.; Caneva, S.; Blume, R.; Robertson, J.; Schloegl, R.; Hofmann, S. Long-Term Passivation of Strongly Interacting Metals with Single-Layer Graphene. J. Am. Chem. Soc. 2015, 137, $14358-14366$.

5. Boscoboinik, J. A.; Shaikhutdinov, S. Exploring Zeolite Chemistry with the Tools of Surface Science: Challenges, Opportunities, and Limitations. Catal. Lett. 2014, 144, 1987-1995.

6. Büchner, C.; Lichtenstein, L.; Yu, X.; Boscoboinik, J. A.; Yang, B.; Kaden, W. E.; Heyde, M.; Shaikhutdinov, S. K.; Włodarczyk, R.; Sierka, M., et al. Ultrathin Silica Films: The Atomic Structure of Two-Dimensional Crystals and Glasses. Chem. A Eur. J. 2014, 20, 9176-9183.

7. Weissenrieder, J.; Kaya, S.; Lu, J. L.; Gao, H. J.; Shaikhutdinov, S.; Freund, H. J.; Sierka, M.; Todorova, T. K.; Sauer, J. Atomic Structure of a Thin Silica Film on a Mo(112) Substrate: A Two-Dimensional Network of $\mathrm{SiO}_{4}$ Tetrahedra. Phys. Rev. Lett. 2005, 95, 076103. 
8. Stacchiola, D.; Kaya, S.; Weissenrieder, J.; Kuhlenbeck, H.; Shaikhutdinov, S.; Freund, H.-J.; Sierka, M.; Todorova, T. K.; Sauer, J. Synthesis and Structure of an Ultra-Thin Aluminosilicate Film. Angew. Chem. Int. Ed. 2006, 45, 7636-7639.

9. Kundu, M.; Murata, Y. Growth of Single-Crystal $\mathrm{SiO}_{2}$ Film on Ni(111) Surface. Appl. Phys. Lett. 2002, 80, 1921-1923.

10. Zhang, Z.; Jiang, Z.; Yao, Y.; Tan, D.; Fu, Q.; Bao, X. Preparation and Characterization of Atomically Flat and Ordered Silica Films on a Pd(100) Surface. Thin Solid Films 2008, 516, 3741-3746.

11. Yu, X.; Yang, B.; Boscoboinik, J. A.; Shaikhutdinov, S.; Freund, H.-J. Support Effects on the Atomic Structure of Ultrathin Silica Films on Metals. Appl. Phys. Lett. 2012, 100, 151608-4.

12. Boscoboinik, J. A.; Yu, X.; Yang, B.; Fischer, F. D.; Włodarczyk, R.; Sierka, M.; Shaikhutdinov, S.; Sauer, J.; Freund, H.-J. Modeling Zeolites with Metal-Supported Two-Dimensional Aluminosilicate Films. Angew. Chem. Int. Ed. 2012, 51, 6005-6008. 13. Yang, B.; Kaden, W. E.; Yu, X.; Boscoboinik, J. A.; Martynova, Y.; Lichtenstein, L.; Heyde, M.; Sterrer, M.; Wlodarczyk, R.; Sierka, M., et al. Thin Silica Films on $\mathrm{Ru}(0001)$ : Monolayer, Bilayer and Three-Dimensional Networks of $\left[\mathrm{SiO}_{4}\right]$ Tetrahedra. Phys. Chem. Chem. Phys. 2012, 14, 11344-11351.

14. Schlexer, P.; Pacchioni, G.; Włodarczyk, R.; Sauer, J. CO Adsorption on a Silica Bilayer Supported on Ru(0001). Surf. Sci. 2016, 648, 2-9. 
15. Emmez, E.; Boscoboinik, J. A.; Tenney, S.; Sutter, P.; Shaikhutdinov, S.; Freund, H.-J. Oxidation of the Ru(0001) Surface Covered by Weakly Bound, Ultrathin Silicate Films. Surf. Sci. 2016, 646, 19-25.

16. Emmez, E.; Yang, B.; Shaikhutdinov, S.; Freund, H.-J. Permeation of a Single-Layer $\mathrm{SiO}_{2}$ Membrane and Chemistry in Confined Space. J. Phys. Chem. C 2014, 118, 29034-29042.

17. Choi, M.; Na, K.; Kim, J.; Sakamoto, Y.; Terasaki, O.; Ryoo, R. Stable Single-Unit-Cell Nanosheets of Zeolite MFI as Active and Long-Lived Catalysts. Nature 2009, 461, 246-249.

18. Rangnekar, N.; Shete, M.; Agrawal, K. V.; Topuz, B.; Kumar, P.; Guo, Q.; Ismail, I.; Alyoubi, A.; Basahel, S.; Narasimharao, K., et al. 2D Zeolite Coatings: LangmuirSchaefer Deposition of $3 \mathrm{~nm}$ Thick MFI Zeolite Nanosheets. Angew. Chem. Int. Ed. $\mathbf{2 0 1 5}, 54,6571-6575$.

19. Xomeritakis, G.; Lai, Z.; Tsapatsis, M. Separation of Xylene Isomer Vapors with Oriented MFI Membranes Made by Seeded Growth. Ind. Eng. Chem. Res 2001, 40, $544-552$.

20. Ren, L.; Guo, Q.; Kumar, P.; Orazov, M.; Xu, D.; Alhassan, S. M.; Mkhoyan, K. A.; Davis, M. E.; Tsapatsis, M. Self-Pillared, Single-Unit-Cell Sn-MFI Zeolite Nanosheets and Their Use for Glucose and Lactose Isomerization. Angew. Chem. Int. Ed. 2015, 54, 10848-10851. 
21. Löffler, D.; Uhlrich, J. J.; Baron, M.; Yang, B.; Yu, X.; Lichtenstein, L.; Heinke, L.; Büchner, C.; Heyde, M.; Shaikhutdinov, S., et al. Growth and Structure of Crystalline Silica Sheet on Ru(0001). Phys. Rev. Lett. 2010, 105, 146104.

22. Boscoboinik, J. A.; Yu, X.; Yang, B.; Fischer, F. D.; Włodarczyk, R.; Sierka, M.; Shaikhutdinov, S.; Sauer, J.; Freund, H.-J. Modeling Zeolites with Metal-Supported Two-Dimensional Aluminosilicate Films. Angew. Chem. Int. Ed. 2012, 51, 6005-6008. 23. Lindroos, M.; Pfnür, H.; Held, G.; Menzel, D. Adsorbate Induced Reconstruction by Strong Chemisorption: Ru(001)p(2×2)-O. Surf. Sci. 1989, 222, 451-463.

24. Pfnür, H.; Held, G.; Lindroos, M.; Menzel, D. Oxygen Induced Reconstruction of a Close-Packed Surface: A Leed IV Study on Ru(001)-p(2 × 1)O. Surf. Sci. 1989, 220, 43-58.

25. Kostov, K. L.; Gsell, M.; Jakob, P.; Moritz, T.; Widdra, W.; Menzel, D. Observation of a Novel High Density $3 \mathrm{O}(2 \times 2)$ Structure on Ru(001). Surf. Sci. 1997, 394, L138-L144.

26. Stampfl, C.; Schwegmann, S.; Over, H.; Scheffler, M.; Ertl, G. Structure and Stability of a High-Coverage (1x1) Oxygen Phase on Ru(0001). Phys. Rev. Lett. 1996, 77, 3371-3374.

27. Włodarczyk, R.; Sierka, M.; Sauer, J.; Löffler, D.; Uhlrich, J. J.; Yu, X.; Yang, B.; Groot, I. M. N.; Shaikhutdinov, S.; Freund, H. J. Tuning the Electronic Structure of Ultrathin Crystalline Silica Films on Ru(0001). Phys. Rev. B 2012, 85, 085403. 
28. Blume, R.; Hävecker, M.; Zafeiratos, S.; Teschner, D.; Kleimenov, E.; Knop-Gericke, A.; Schlögl, R.; Barinov, A.; Dudin, P.; Kiskinova, M. Catalytically Active States of $\mathrm{Ru}(0001)$ Catalyst in CO Oxidation Reaction. J. Catal. 2006, 239, 354-361.

29. Starr, D. E.; Bluhm, H. CO Adsorption and Dissociation on Ru(0001) at Elevated Pressures. Surf. Sci. 2013, 608, 241-248.

30. Klemm, H. W.; Peschel, G.; Madej, E.; Fuhrich, A.; Timm, M.; Menzel, D.; Schmidt, T.; Freund, H. J. Preparation of Silica Films on Ru(0001): A LEEM/PEEM Study. Surf. Sci. 2016, 643, 45-51.

31. Over, H.; Seitsonen, A. P.; Lundgren, E.; Smedh, M.; Andersen, J. N. On the Origin of the $\mathrm{Ru}-3 \mathrm{~d}_{5 / 2}$ Satellite Feature from $\mathrm{RuO}_{2}\left(\begin{array}{lll}1 & 1 & 0\end{array}\right)$. Surf. Sci. 2002, 504, L196-L200.

32. Flege, J. I.; Herd, B.; Goritzka, J.; Over, H.; Krasovskii, E. E.; Falta, J. Nanoscale Origin of Mesoscale Roughening: Real-Time Tracking and Identification of Three Distinct Ruthenium Oxide Phases in Ruthenium Oxidation. ACS Nano 2015, 9, 8468-8473.

33. Goritzka, J. C.; Herd, B.; Krause, P. P. T.; Falta, J.; Flege, J. I.; Over, H. Insights into the Gas Phase Oxidation of $\mathrm{Ru}(0001)$ on the Mesoscopic Scale Using Molecular Oxygen. Phys. Chem. Chem. Phys. 2015, 17, 13895-13903. 
34. Kumar, P.; Agrawal, K. V.; Tsapatsis, M.; Mkhoyan, K. A. Quantification of Thickness and Wrinkling of Exfoliated Two-Dimensional Zeolite Nanosheets. Nat. Commun. 2015, 6, 7128.

35. Over, H.; Seitsonen, A. P. Oxidation of Metal Surfaces. Science 2002, 297, 2003-2005. 
TOC GRAPHICS

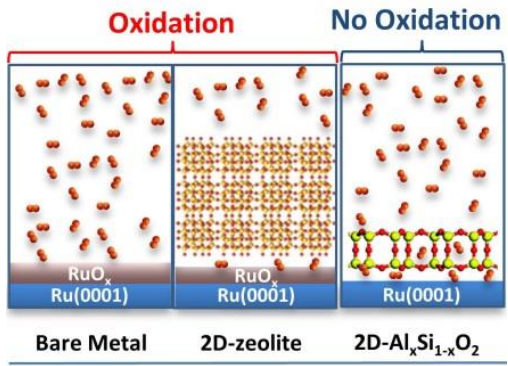

$820 \mathrm{~K}$

$10^{-4} \mathrm{mbar} \mathrm{O}_{2}$ oxygen 